\title{
"A carne mais barata do mercado é a carne negra1": uma reflexão sobre o "design" das camisas da Puma na Copa do Mundo de Futebol/ 2010
}

CDD. 20.ed. 616.89

796.05
Victor Andrade de MELO*

Fabiana RESENDE*

Alexandre PALMA*

Monique ASSIS ${ }^{* *}$
*Universidade Federal do Rio de Janeiro.

**Universidade Gama

Filho.

\section{Resumo}

A Puma, uma empresa de material esportivo, desde meados da primeira década do século XXI tem constantemente utilizado jogadores negros em suas campanhas publicitárias, parte de uma estratégia de busca de aproximação com o continente africano. À beira da falência no início dos anos 90, a empresa conseguiu se reposicionar no mercado unindo o esporte à moda, investindo em produtos de "design" arrojado. Uma de suas iniciativas foi buscar inspiração no "caráter exótico" das nações africanas para produzir peças que possam ser utilizadas em situações cotidianas, não só para a prática de esportes. Como o corpo do negro africano tem sido representado em suas estratégias publicitárias? Esse estudo teve por objetivo analisar um ponto específico da publicidade da Puma por ocasião da Copa do Mundo de Futebol de 2010, realizada na África do Sul: o "design" das camisas fornecidas a três seleções africanas - Camarões, Costa do Marfim e Gana. Para alcance do objetivo, entabulamos uma comparação com os modelos das camisas fornecidas pela empresa a outros selecionados (Suiça, Uruguai e Itália), prospectando o quanto suas ações publicitárias reforçam ou não certos estereótipos comumente observados quando se utilizam negros em campanhas de publicidade.

UnIteRmos: Corpo; Publicidade; África.

\section{Introdução}

As competições esportivas internacionais vêm assumindo dimensões cada vez maiores. Cercadas por estratégias comerciais refinadas, alicerçadas em uma criativa e intensa publicidade, não seria equivocado dizer que, nos dias de hoje, o consumo é um dos principais elementos constituintes desses espetáculos de cifras milionárias. Nesse quadro, os espectadores se consolidaram como atores importantes, parte fundamental dos eventos esportivos.

Entre os esportes, o futebol merece destaque por sua popularidade e presença mundial; basta dizer, a título de exemplo, que a FIFA tem mais associados do que a ONU. Por isso mesmo, uma Copa do Mundo é um imenso caldeirão de identidades (RAMOS, 2010), continuamente celebradas e tensionadas a cada rodada, a cada partida. Como lembra Новsвашм (2007), mesmo que a lógica transnacional e os interesses econômicos imperem também no reino do esporte:

os imperativos não-econômicos da identidade nacional têm tido força suficiente para afirmar-se no contexto do jogo e mesmo para impor o torneio internacional de seleçôes, a Copa do Mundo, como o elemento principal e mais poderoso da presença econômica global do futebol (p.94)

Esse cenário torna-se mais complexo com o fenômeno da "migração" de jogadores, normalmente oriundos de países da América Latina e da África, contratados por clubes europeus. Vestindo a camisa de grandes equipes, esses atletas, comumente de origem humilde, podem se tornar celebridades mundiais cobiçadas pelas grandes empresas. Associados a produtos oferecidos em campanhas publicitárias, são apresentados como indivíduos bem sucedidos, 
transformando-se em verdadeiros ícones populares (PolI, 2006).

Curiosamente, diferentemente da maior parte das campanhas publicitárias, que utilizam predominantemente modelos brancos como personagens principais, os anúncios relacionados ao futebol também utilizam com constância a imagem de jogadores negros.

De um lado, isso pode se dever ao fato de o atleta, independentemente da cor de sua pele, passar por um processo de mitificação. Assim, não o negro estaria estampando num anúncio, mas sim o mito (Toledo, 2004). De outro lado, é inegável que as estratégias publicitárias têm em conta tanto supostos "potenciais representacionais" dos negros (isso é, a possibilidade de suas imagens serem apreendidas para expressar algo específico) quanto o aumento do mercado a ser atingido.

Não se pode desprezar também as possíveis respostas às reivindicações de movimentos sociais, consideradas por certas instâncias esportivas tendo em conta não macular sua imagem historicamente construída, pelo menos no âmbito dos discursos, de adesão a princípios democráticos e saudáveis.

De qualquer forma, parece irrefutável que a publicidade pode valer-se de determinados estereótipos relacionados ao corpo negro para promover seus produtos (CATHUS, 2006).
A Puma, uma empresa de material esportivo, desde meados da primeira década do século XXI tem constantemente utilizado jogadores negros em suas campanhas publicitárias, parte de uma estratégia de busca de aproximação com o continente africano. À beira da falência no início dos anos 90, a empresa conseguiu se reposicionar no mercado unindo o esporte à moda, investindo em produtos de design arrojado. Uma de suas iniciativas foi buscar inspiração no "caráter exótico" das nações africanas para produzir peças que possam ser utilizadas em situações cotidianas, não só para a prática de esportes (FerRaresi, Franzoni, Helou FIlho, Rothbarth, Otani, Wolf \& Francisco, 2010).

Como o corpo do negro africano tem sido representado em suas estratégias publicitárias? Esse estudo teve por objetivo analisar um ponto específico da publicidade da Puma por ocasião da Copa do Mundo de Futebol de 2010, realizada na África do Sul: o "design" das camisas fornecidas a três seleçōes africanas - Camarões, Costa do Marfim e Gana.

Para alcance do objetivo, entabulamos uma comparação com os modelos das camisas fornecidas pela Puma a outros selecionados (Suíça, Uruguai e Itália), prospectando o quanto suas ações publicitárias reforçam ou não certos estereótipos comumente observados quando se utilizam negros em campanhas de publicidade.

\section{Publicidade e modelos corporais}

A publicidade e a propaganda expressam um quadro de tensôes entre os desejos individuais e os desejos coletivos gerados em um determinado contexto. Mais do que produtos, os anúncios apresentam estilos de vida, visões de mundo, sentimentos (VelHo \& BaCelLaR, 2003); representam comportamentos e valores, tanto induzidos quanto reflexos:

A mensagem publicitária se dirige ao conjunto de imagens, símbolos, desejos e medos que, embora variem um pouco, de pessoa para pessoa, constituem um novo padrão cultural de cada sociedade, chamado de imaginário pelos estudiosos das ciências humanas. Esse imaginário não é estático, assim reorganizado conforme as necessidades e características de cada momento histórico (CERRI, 2006, p.84).

BELELI (2007) destaca o papel fundamental do corpo no que se refere ao processo de identificação com a marca promovido pelo anúncio. Tal representação corporal pode gerar repulsa ou atração; comumente, de qualquer forma, causa fascínio. Majoritariamente, por certo, privilegiam-se modelos corporais idealizados, um padrão de beleza pautado, não poucas vezes, por referências europeias (MALDONADO, 2006).

Os "corpos desviantes", como os de pessoas com sobrepeso, geralmente apresentam o "pólo negativo", aquilo que precisa ser superado. Por exemplo, como demonstram Palma, Assis, Lacerda, Bagrichevsky e SAMPAIO (2010), em um estudo sobre as estratégias discursivas de uma revista feminina brasileira de grande circulação, nas poucas matérias que tratavam de pessoas acima do peso, as "gordinhas" foram fotografadas com pouca ou nenhuma maquiagem e com roupas compridas, deixando à mostra apenas o rosto e, às vezes, parte do antebraço; acompanhavam as imagens mensagens como "bem vinda ao desafio do clube da gordinha" e "a batalha contra a balança começa aqui! Pegue carona".

É ainda comum em matérias desse gênero a presença de fotos do "antes e depois" de algum programa de dietas ou exercícios: a imagem do "depois" mostra a mesma pessoa bem maquiada, com roupas mais chamativas e curtas. 
São flagrantes também as diferenças no trato dos corpos de homens e mulheres. Enquanto os primeiros são apresentados como possuidores de inteligência, as mulheres comumente são representadas apenas como um corpo que deve seguir determinados padróes de beleza (PALMA et al., 2010).

Ainda que as imagens masculinas sejam também pautadas por um modelo de beleza, não é nela que se ancora a ideia de virilidade, essa sim uma dimensão valorizada. A masculinidade estaria melhor expressa no desempenho e na determinação (SABAT, 2003), que sustentariam uma condição de liderança social (BELELI, 2007).

Os negros também passam por processo semelhante de diferenciação. Em campanhas publicitárias veiculadas até a primeira metade da década de 80 , predominavam os anúncios em que eram retratados em duas situaçóes: exercendo o papel de coadjuvante, como serviçais, motoristas ou outras atividades consideradas de menor prestígio social; ou quando os produtos estavam voltados especificamente para consumidores negros, não poucas vezes aproximados do ideal branco de beleza (Pacheco, 2001; Strozenberg, 2005).

Negros só passaram a protagonizar anúncios de produtos e serviços voltados para o consumidor em

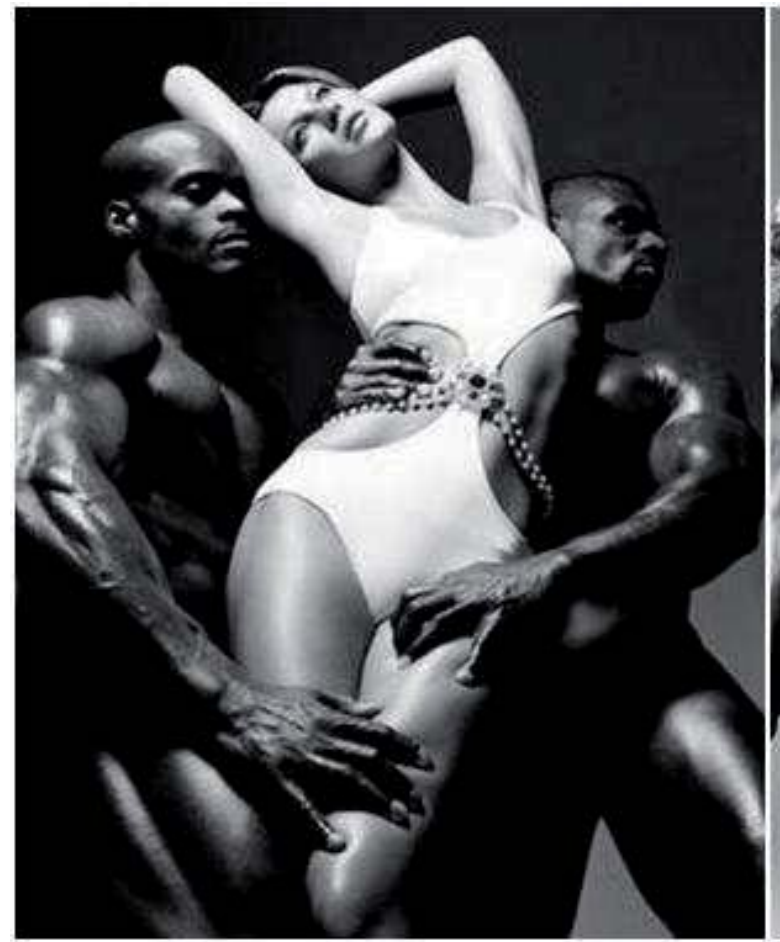

geral a partir do momento em que as agências publicitárias perceberam a expansão da classe média negra, além de entenderem que isso poderia ser um componente agregador de valores (STROZENBERG, 2006).

De qualquer forma, em estudo sobre a revista Boa Forma, Palma et al. (2010) observaram que de 1.633 imagens corporais publicadas, somente $1,22 \%$ eram de negros. Já Duerksen, Mikail, Tom, Patton, Lopez, Amador, Vargas, Victorio, Kustin e SADLER (2005), em pesquisa sobre revistas femininas norte-americanas, constataram que, comparados aos sujeitos de pele branca, os negros tinham suas fotografias mais associadas a mensagens potencialmente nocivas à saúde.

Assim, apesar de ter conquistado o papel principal em algumas campanhas publicitárias, o negro continua ocupando menor espaço, sendo estigmatizado e estereotipado, não poucas vezes como violento, selvagem, insaciável sexualmente, malandro. As mulheres negras, em especial, são caracterizadas como sensuais, tendo seus corpos fortemente erotizados (Roso, Strey, Guareschi \& Bueno, 2002).

Vejamos um exemplo: um ensaio fotográfico realizado pelo norueguês Solvo Sundsbo, protagonizado por Gisele Bündchen (FIGURA 1).

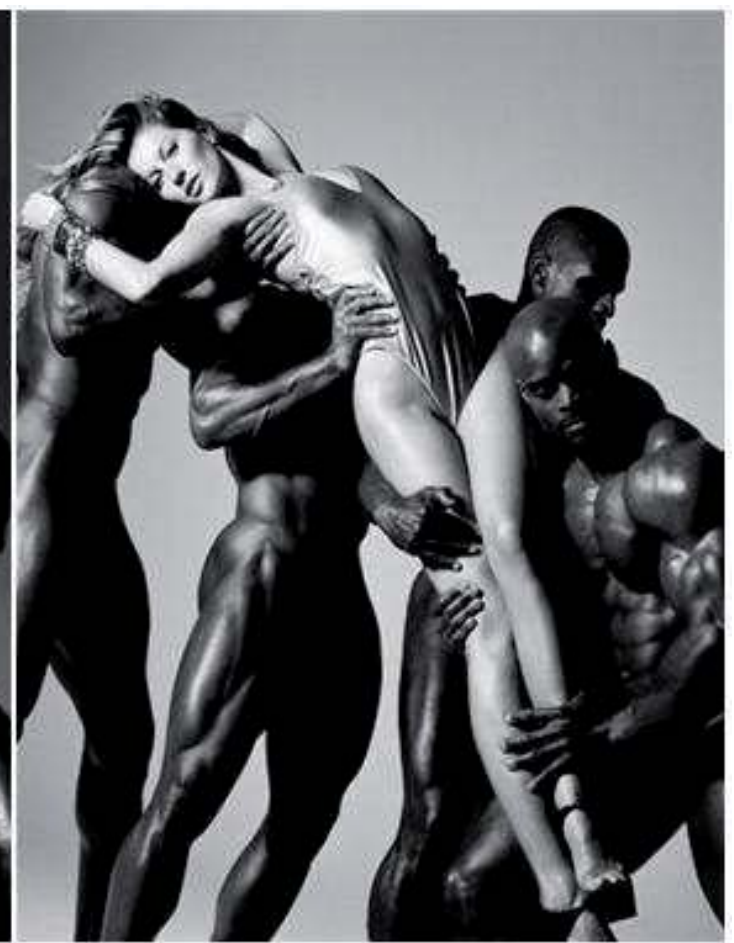

FIGURA 1 - Gisele Bünchen e modelos negros protagonizam ensaio fotográfico (GISELE, 2009).

Insinuantemente intitulado "Fashion Porn", o ensaio exibe imagens da brasileira rodeada por negros musculosos, denotando sensualidade e desejo sexual. Enquanto a modelo branca traja roupas de banho e joias (que lembram correntes), os negros estão completamente nus: o civilizado e o selvagem, o religioso e o pagão; um contraste inegavelmente belo, mas que certamente reforça estereótipos. 


\section{J ogadores negros africanos e o futebol mundial}

Em seu formato moderno, um fenômeno que se delineou na Inglaterra da transição dos séculos XVIII e XIX, imerso no quadro de amplas mudanças que marcaram a construção material e simbólica da modernidade, o esporte, em cujas origens e trajetória se confundem apreensões de populares e das elites (notadamente por parte da burguesia e do operariado, as classes por excelência que emergiram no novo contexto), se espraiou pelo planeta no bojo do processo de mundialização e de desenvolvimento do comércio internacional que marcou aquele momento (MELO, 2010).

Assim como em outros lugares do mundo, a prática esportiva também desembarcou no continente africano, nesse caso inserida no quadro de tensōes coloniais, de acordo com a colônia/colonizado/colonizador significando ferramenta de controle, marca de distinção do dominador, forma de autoidentificação de uma elite local, até mesmo estratégia de resistência e preparação de lutas políticas (MELO, 2011).

Por sua projeção internacional e potencial de mobilização, o esporte desempenhou um papel significativo na constituição da ideia de nação. Essa dimensão é bastante notável no caso dos jovens países da África. Como lembra HoBSBAWM: "a existência da seleção nacional de futebol estabeleceu, em alguns casos pela primeira vez, uma identidade nacional independente das identidades locais, tribais ou religiosas" (2007, p.95).

De um lado, em muitas naçóes africanas, os novos heróis esportivos foram fundamentais nos processos de construção e consolidação de sentidos de nacionalidade:

A partir dos anos 1970, atletas africanos tornaram-se símbolos de identidade nacional (...). Eles eram altamente visíveis, e com a vantagem adicional de que sua fama apolítica não poderia ser contestada. Ainda mais que os heróis políticos, os atletas representavam um tipo de sucesso que estava ostensivamente apresentado como de alcance de um grande número de jovens africanos (BAKER, 1987, p.273).

De outro lado, a prática esportiva estabeleceu importantes interfaces com o contexto mundial: a longo prazo, a função mais importante do futebol e outros esportes na África deve estar relacionada ao seu potencial como meio de comunicação entre culturas. Especificamente, a atenção global que é dada às estrelas esportivas, a constante cobertura mediática dos atletas de elite, fornece uma ponte de mediação entre o mundo em desenvolvimento e os países desenvolvidos (GiulianotTi, 1999).
Nas últimas décadas, com o crescimento e a melhor estruturação do mercado internacional esportivo, crescentemente o continente africano tem sido envolvido por estratégias comerciais. Uma das facetas desse processo é a contratação de jogadores por clubes europeus.

O recrutamento de jogadores africanos já era observado no período colonial, mas foi mesmo a partir das décadas de 70 e 80 que, atraídos pela oferta de altos salários e boa estrutura de trabalho, mais atletas passaram a defender equipes de outros países, muitas vezes das naçōes outrora colonizadoras, onde, supostamente, as diferenças culturais e linguísticas são amenizadas (Darby, 2006; DarbY, AKINDES \& KirWIN, 2007).

Progressivamente isso se torna um sonho para muitos africanos, que vislumbram aí uma possibilidade de escapar das difíceis condiçôes de vida às quais ainda está submetida grande parte da população do continente, que possui alguns dos países mais pobres do planeta.

Não surpreende que alguns autores encarem essa ocorrência como uma manifestação de neocolonialismo, a continuidade de exercício de poder sob novas bases, de coerção menos explícita, por isso mesmo tão ou mais cruel do que as antigas exibiçôes de força do período colonial:

A sistematização do recrutamento, migração e trabalho dos jogadores africanos de futebol pode ser vista como uma forma de neocolonialismo (...). Gostaria de ilustrar o neocolonialismo das migraçōes de jogadores africano por meio de três exemplos. $\mathrm{O}$ primeiro é a criação de "clubes fazendas" pelos megaclubes na África, o segundo é a exploração de jovens africanos recrutados na Europa e o terceiro faz alusão ao papel de "agentes" no aproveitamento dos talentos esportivos africanos domiciliados em Europa (BALE, 2004, p.237).

Além disso, não se deve desprezar o fato de que tal migração tem sido, ainda que não o único, um dos importantes elementos que contribui para o não completo desenvolvimento do esporte no continente africano (DARBY, 2006).

Obviamente que nem tudo é negativo. ArmsTRONG e GiulianotTi (2004) inferem que, ainda que o futebol tenha sido e siga sendo utilizado como instrumento para implementação de estratégias coloniais, pós-coloniais e neocoloniais:

O sistema internacional de futebol não é totalmente negativo para os jovens jogadores africanos. Para os poucos que conseguem, status 
social e segurança econômica seguem ao lado do prazer de jogar regularmente. Para muitos, é melhor ficar no Ocidente e trabalhar do que voltar a uma nação em grande declínio. Para os milhões que não conseguem ser selecionados, o futebol representa uma experiência de lazer agradável e um passatempo social (p.11).

É interessante observar que o aumento da visibilidade dos jogadores africanos tem sido acompanhado por um crescimento do protagonismo de nações do continente em entidades esportivas internacionais, notável a partir da eleição de João Havelange para a presidência da FIFA, em 1974 (DARBY, 2002).

Nesse quadro, alguns jogadores, aqueles que alcançam os patamares mais altos da profissão, chegam a ganhar mais dinheiro com publicidade do que com os salários propriamente ditos. Esse é o caso de Didier Drogba, atacante do Chelsea, nascido na Costa do Marfim, que, segundo a revista France Football, em 2009 arrecadou 5.800.000€ com publicidade e patrocínios, e 4.900.000 € na forma de salário (20 JogAdOREs, 2009).

No entanto, vale observar que há poucos africanos entre os 50 maiores salários de jogadores no futebol europeu na temporada 2009/2010: Samuel Eto'o, atacante camaronês; o togolês Emmanuel Adebayor; Kolo Touré, zagueiro marfinense; Frederic Kanouté, malinês com cidadania francesa; além do já citado Didier Drogba (50 MaIORES, 2010).

De qualquer forma, tendo em conta que os jogadores de futebol são considerados por um segmento do público, especialmente crianças e jovens, como exemplos (GUerra, 2003), esses poucos atletas africanos que ganham destaque mundial tornam-se símbolos de sucesso, alimentando o imaginário de que é possível ascender socialmente e sendo mobilizados na construção de identidades nacionais.

$\mathrm{Na}$ verdade, defendendo clubes que possuem fãs espalhados pelo mundo, tornam-se ídolos planetários, exercendo influência não só sobre seus compatriotas. De fato, esses atletas parecem transcender suas nacionalidades e tornam-se "produtos" globalizados.

Como teriam sido representados os jogadores africanos negros por ocasião da Copa do Mundo de 2010, nas iniciativas publicitárias de uma importante empresa de materiais esportivos, a Puma? Vamos discutir um aspecto específico: o design das camisas de três seleçôes africanas: Camarões, Costa do Marfim, Gana.

\section{Selvagem e sensual: a velha representação}

Atraindo seguidores apaixonados por todo o planeta, o futebol conforma um considerável nicho de mercado, no qual os produtos relacionados aos clubes, seleções e atletas são cobiçados. Entre tantos itens desejados e rentáveis, as camisas das equipes destacam-se pelo potencial de expressar as vinculações dos indivíduos que as portam.

No período que antecede cada Copa do Mundo, é elevada a expectativa com os novos modelos das camisas das seleções participantes. Mesmo que haja limites para as modificações, em função das regras da FIFA (CATHUS, 2006), inovações no "design" são constantes.

Os uniformes das seleções participantes da Copa do Mundo de 2010 foram fornecidos por sete marcas esportivas. A TABELA 1 apresenta a distribuição dos patrocinadores e os continentes das equipes nacionais. No caso da Puma, do total de sete selecionados que receberam seus materiais esportivos, quatro eram africanos; foi a empresa que mais patrocinou times da África.

TABELA 1 - Distribuição das empresas esportivas fornecedoras dos uniformes por continentes das seleções nacionais.

\begin{tabular}{|c|c|c|c|c|c|c|c|c|c|c|c|c|}
\hline \multirow{3}{*}{$\begin{array}{l}\text { Empresas } \\
\text { esportivas }\end{array}$} & \multicolumn{12}{|c|}{ Continentes } \\
\hline & \multicolumn{2}{|c|}{ Total } & \multicolumn{2}{|c|}{ Américas } & \multicolumn{2}{|c|}{ Europa } & \multicolumn{2}{|c|}{ África } & \multicolumn{2}{|c|}{ Ásia } & \multicolumn{2}{|c|}{ Oceania } \\
\hline & $\mathbf{n}$ & $\%$ & $\mathbf{n}$ & $\%$ & $\mathbf{n}$ & $\%$ & $\mathbf{n}$ & $\%$ & $\mathbf{n}$ & $\%$ & $\mathbf{n}$ & $\%$ \\
\hline Adidas & 12 & 37,5 & 3 & 25,0 & 6 & 50,0 & 2 & 16,7 & 1 & 8,3 & 0 & 0,0 \\
\hline Nike & 9 & 28,1 & 2 & 22,2 & 4 & 44,4 & 0 & 0,0 & 1 & 11,1 & 2 & 22,2 \\
\hline Puma & 7 & 21,9 & 1 & 14,3 & 2 & 28,6 & 4 & 57,1 & 0 & 0,0 & 0 & 0,0 \\
\hline Outros & 4 & 12,5 & 2 & 50,0 & 1 & 25,0 & 0 & 0,0 & 1 & 25,0 & 0 & 0 \\
\hline
\end{tabular}


A Puma desenvolveu para três dos quatro selecionados africanos que patrocinou, justamente aqueles compostos majoritariamente por jogadores negros (Camarôes, Costa do Marfim e Gana), camisas com uma modelagem mais ajustada ao corpo (FIGURA

2). Como se observa no sítio da empresa:

O novo vestuário, mais uma vez empurra os limites da tecnologia e desenho. As camisetas são ajustadas e estão feitas para seguir o contorno do corpo dos esportistas e assim acentuar sua musculatura. Feitas de Power Mesh absorvente, as camisetas contam com uma malha de mesh nas costas, permitindo um maior movimento e respiração. No mesmo mesh traseiro aplicamos um padrão KINTE, inspirado nas telas tradicionais africanas (PUMA BRASIL, 2010a).

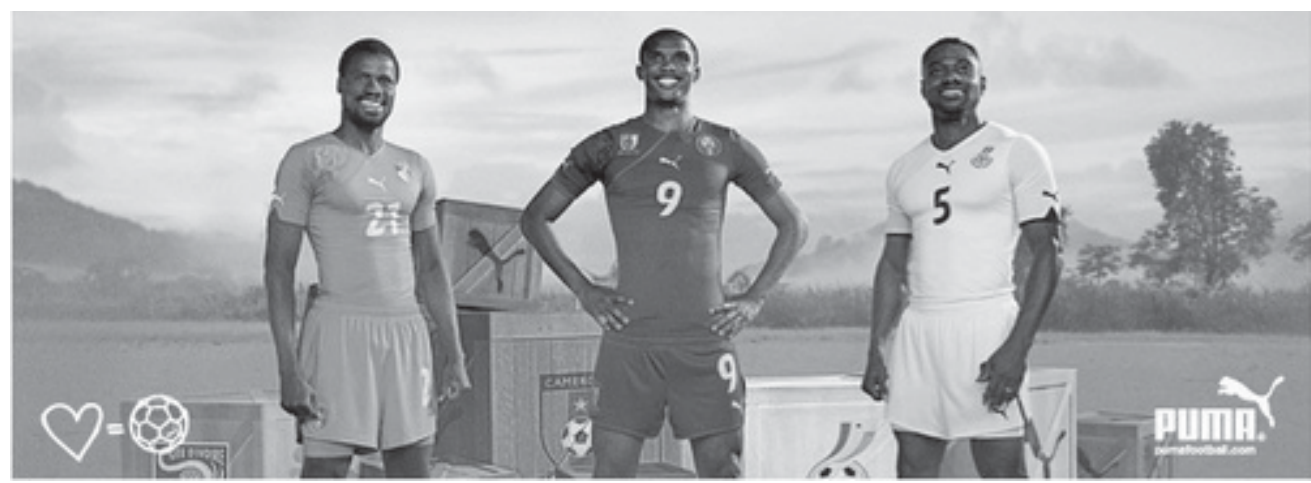

FIGURA 2 - Peça da campanha publicitária desenvolvida pela Puma para a divulgação das camisetas das seleções africanas para a Copa do Mundo da África do Sul, em 2010 (PUMA BRASIL, 2010a).

Sobre a estratégia de marketing da Puma para a Copa do Mundo da África do Sul, comentam Boechat e Cardoso (2010):

Inteligente também foi a estratégia utilizada pela Puma para conseguir seu espaço na Copa do Mundo sem precisar, é claro, pagar à Fifa. A companhia alemã, nascida na mesma cidade da Adidas, é a que conta com o menor faturamento entre as três (US\$ 3,2 bilhôes) e decidiu adotar uma estratégia semelhanteà da Nike, mas no segmento de camisas. Patrocinadora de quatro das seis seleçóes africanas que disputam este Mundial, a companhia desenhou uniformes que deixam à mostra a musculatura dos jogadores africanos. Cada camisa é quase uma segunda pele, justíssima, diferenciando-se dos tradicionais uniformes da Adidas e da Nike.
O resultado dessa estratégia, que começou há cinco anos, é que a Puma é uma das marcas esportivas com maior penetração no mundo da moda de rua, com clientes que, na maioria das vezes, não têm uma ligação direta com o futebol. Segundo a empresa, as camisas não têm apenas uma conotação fashion. O modelo, assegura a fabricante, reduz a vibração muscular e aumenta a explosão do jogador. É impossível saber se a tecnologia funciona mesmo. Mas, que chama a atenção, é inegável.

Quando comparamos essas camisas às fornecidas a outros selecionados, até mesmo àqueles que também recebem material esportivo da Puma, como é o caso da Suíça, da Itália e do Uruguai (que podemos ver na FIGURA 3), percebemos as diferenças: ao contrário do modelo justo, o corte é reto e mais folgado.

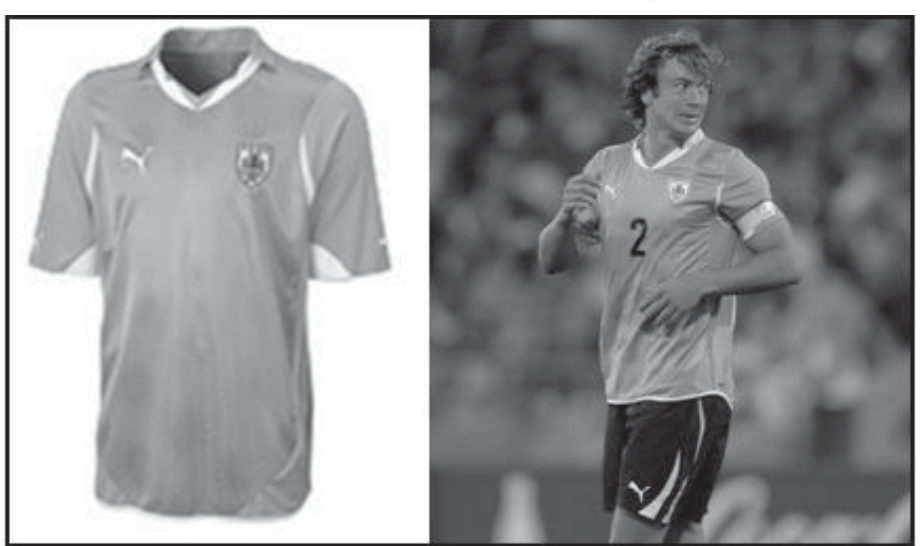

FIGURA 3 - Camisa desenvolvida pela Puma para a seleção do Uruguai para a Copa do Mundo da África do Sul, em 2010 (Fotos, 2010; Puma Brasil, 2010b). 
As opiniōes do público e de especialistas nos leva a crer que as camisas confeccionadas pela Puma para as três seleçôes africanas parecem ter atingido seus objetivos. Por exemplo, em uma matéria sobre os jogadores mais belos da Copa do Mundo, uma mulher expõe sua opinião sobre os atletas da equipe da Costa do Marfim: "Aqueles negões com camisas coladas são o máximo" (Honorato, 2010). O "design" também chamou a atenção de VASCONCELOS (2010):

Dona da modelagem mais ajustada de todas, desenhou para esse mundial a imagem de verdadeiros deuses contemporâneos do futebol. A estratégia tomada pela marca de Rudolf foi apresentar menos opções que a concorrência, mantendo exatamente a mesma base para as seleções africanas de Gana, Costa do Marfim, Argélia e Camarōes.

Assim, indubitavelmente, o conjunto "camisa de modelagem ajustada/corpos musculosos" resultou em um forte apelo estético e em um eficaz veículo de propaganda da marca esportiva. Todavia, é também inegável que reforça estereótipos ligados ao futebol africano e aos negros em geral: agressivo, selvagem, sensual.

Essa linha de ação da Puma não é recente. A empresa causou polêmica em pelo menos duas ocasiōes: na Copa do Mundo de 2002, quando equipou a seleção camaronesa com camisetas sem mangas; e quando criou, para o mesmo selecionado atuar na Copa da África, um uniforme composto por calção e camisa em peça única, chamado "all-in-one" (CATHUS, 2006). No primeiro caso, os jogadores participaram da competição usando uma camisa de mangas por baixo; no segundo caso, a equipe chegou a sofrer uma sanção, depois anulada por recurso (CATHUS, 2006).

$\mathrm{Na}$ verdade, a aproximação da Puma com o continente africano, segundo Giardina (2010), pode ser entendida no quadro de uma série de iniciativas empresarias e de lideranças políticas e culturais internacionais que, desde um olhar comumente homogêneo e estereotipado, estabelece o que Hannah Arendt chama de "política de piedade".

Para GiARDINA (2010), essas açôes "filantrocapitalistas", estimuladas por um contexto em que mundialmente tornou-se "chique" entre as classes média e alta demonstrar preocupaçōes, ainda que superficiais, com os "necessitados" e com a construção de "um mundo melhor", escondem um processo de comodificação que tanto torna a África uma marca a ser mundialmente consumida, quanto busca abrir as portas para a geração de um mercado interno que interessa às corporações de capital multinacional.

Desde o momento em que passou por uma crise financeira, para se reposicionar no mercado mundial, a Puma tem adotado posturas que supostamente estimulam o consumo consciente e buscam se vincular a movimentos internacionais de sustentabilidade, tendo nos últimos anos logrado reconhecimento por suas açōes. Nesse quadro, desde 2006 tem patrocinado seleçōes e jogadores africanos, como Samuel Eto'o. O discurso da empresa é que a África, um mercado em potencial, precisa ser ajudada em seus esforços de consolidação da democracia e superação das suas mazelas sociais. Para GiaRdina (2010):

Claramente, a Puma não estabelece de forma inconsciente com Eto'o um relacionamento pautado pela mentalidade politicamente consciente. Pode-se dizer que sua política extra-textual de representação da realidade busca imprimir uma mentalidade de ativismo ao rótulo da Puma. Dada essa associação, é muito decepcionante que tenha de fato reforçado estereótipos raciais do atleta negro do sexo masculino na utilização de Eto'o em suas várias campanhas publicitárias (p.137).

Assim, podemos nos perguntar, tanto no caso das camisas da Copa do Mundo de 2010 quanto no caso apontado por GIARDINA (2010): ao reforçar estereótipos a empresa não está explicitando que o que lhe interessa efetivamente é a possibilidade de conquistar um novo mercado e não exatamente, ou ao menos não profundamente, a superação de uma ordem social marcada pela injustiça?

Ainda que não devamos negar possíveis benefícios para os africanos atendidos pelas açôes "filantropocapitalistas", devemos descortinar com mais acuidade o que está por trás dessas supostas "boas intenções", inclusive no que se refere à prática esportiva, comumente considerada como importante ferramenta para a construção de sociedades mais iguais e justas, mas concretamente envolvida por fortes interesses comerciais.

\section{Conclusão}

No exame do "design" das camisas de três dos quatro selecionados africanos que participaram da Copa do Mundo de 2010 e foram patrocinados pela Puma foi possível perceber que foi adotado um modelo que ressaltava os corpos musculosos de atletas negros. Se a combinação "corte justo/corpo musculoso/negro" 
possibilitou maior visibilidade da marca na mídia esportiva, nos meios de comunicação em geral, especialmente nos veículos voltados para a moda, e entre o público como um todo, da mesma forma acabou por reforçar determinados estereótipos acerca dos atletas africanos e dos negros em geral, algo que pode ser observado em outras iniciativas publicitárias.

Na verdade, geralmente jogadores negros, ao contrário dos futebolistas brancos (cujo caso mais paradigmático é o do inglês David Beckham), não são comumente exaltados pela beleza do rosto, pela forma de se vestir ou por sua inteligência, mas sim por sua força física e sua compleição muscular, uma representação que reforça o seu aspecto selvagem, brutal, exótico.

Mais ainda, no que se refere à África, esse conjunto de representações reforça a ideia de uniformidade, ainda que o continente seja bastante heterogêneo e não formado só por países cuja população é majoritariamente negra.
Assim, a ação da Puma no que se refere ao "design" das camisas das três seleçôes patrocinadas se ajusta plenamente a muitas iniciativas empresariais que têm atuado na África: sem considerar as peculiaridades das muitas nações que integram o continente, reforçam uma compreensão homogênea e estereotipada que reforça alguns aspectos negativos: a pobreza, a corrupção, a violência, a fome, a ideia de que há uma incapacidade de as lideranças africanas resolverem seus problemas sem o apoio do ocidente "branco".

Trata-se de uma postura neocolonial claramente delineada, que, ainda que traga alguns benefícios para os africanos, os traz em maior número para as corporações, que logram ganhos de imagem e aumento dos lucros com a incorporação de um novo mercado, sem que sejam oferecidas contribuições efetivas para uma completa mudança no quadro social, econômico e político das muitas nações que compõe a África.

\begin{abstract}
"The cheapest flesh in the market is the black one": body, soccer and advertising Puma uniforms in the 2010 soccer world cup

Puma, a company of sport gears, has been inserting black soccer players in its advertising campaigns as a strategy to get closer to the African continent. Near to bankruptcy at the 90' beginning, the company has succeeded in bringing to the market products with more daring design, linking fashion and sports. One of its latest initiatives was to seek inspiration in the exotic profile of African people to produce pieces that can be used in all occasions not only for sports. How African's bodies have been exposed in its adverting campaigns? The objective of this study was to analyze an specific issue related to some strategies adopted in Puma advertising campaigns launched during 2010 Soccer World Cup in South Africa: the layout of the uniforms offered for three African's teams - Cameroon, Côte d'Ivoire, Ghana. In order to do it, we have established a comparison with the models of shirts fabricated by the company to other national teams (Switzerland, Uruguay and Italy), taking into account the fact that this sort of merchandising may increase or not some stereotypes that are usually associated with black people in advertising campaigns.
\end{abstract}

UnITERMs: Body; Advertising; Africa.

\title{
Notas
}

1. Refrão da canção “A carne”, de autoria de Seu Jorge, Marcelo Yuka e Ulisse Cappelletti, popularizada por interpretaçóes do grupo Farofa Carioca e da cantora Elza Soares.

2. Não devemos desprezar outra ocorrência: a mobilização de identidades nacionais vislumbrando ganhos e interesses econômicos.

3. Entre as seleções africanas, a Puma também forneceu camisas para a seleção da Argélia; essas, todavia, não seguiam o modelo das outras três equipes do continente africano.

4. Segundo SANT’Anna (1997, p.92): “(...) a publicidade, (...) diferentemente da propaganda, incorpora um conjunto de meios destinados a tornar uma determinada empresa conhecida, a vender um certo produto e valorizá-lo”. 
5. A maioria dos países africanos se tornou independente no pós Segunda Grande Guerra.

6. As principais "exportadoras" de jogadores de futebol africanos são as naçōes do norte da África - em especial Tunísia, Egito e Marrocos - e as naçóes da costa subsaariana.

7. Para mais informaçôes sobre o conceito de neocolonialismo, ver Young (2001).

8. Para mais informaçōes sobre as polêmicas acerca da introdução e presença do futebol no continente africano, ver MeLO (2011).

9. A Adidas foi a que mais patrocinou equipes das Américas e da Europa; a Nike foi a que mais forneceu material para selecionados da Oceania.

10. Rudolf Dassler, fundador da Puma era irmão de Adi Dassler, fundador da Adidas.

11. Como visto na nota 3, na verdade, a Argélia recebeu uma camisa distinta.

12. Um debate interessante sobre as Organizações Não-Governamentais que com esporte atuam na África pode ser encontrado na obra de GiUlianotTi (2010).

\section{Referências}

20 JOGADORES que mais ganham no mundo 2009 (com publicidade), Os. Futebol Finance, Lisboa, 2 abr. 2009. Disponível em: $<$ http://www.futebolfinance.com/os-20-jogadores-que-mais-ganham-no-mundo-2009-com-publicidade> Acesso em:20 dez. 2010. 50 MAIORES salários de jogadores de futebol 2009/2001, Os. Futebol Finance, Lisboa, 15 fev. 2010. Disponível em: <http://www.futebolfinance.com/os-50-maiores-salarios-de-jogadores-de-futebol-20092010> Acesso em: 20 dez. 2010. ARMSTRONG, G.; GIULIANOTTI, R. Drama, fields and metaphors: an introduction to football in Africa. In:

(Eds.). Football in Africa: conflict, conciliation and community. New York: Palgrave MacMillan, 2004.

BAKER, W.J. Political games: the meaning of international sport for independent Africa. In: BAKER, W.J.; MANGAN, J.A. (Eds.). Sport in Africa: essays in social history. New York: African Publishing, 1987. p.272-94.

BALE, J. Three geographies of African footballer migration: patterns, problems and postcoloniality. In: ARMSTRONG, G.; GIULIANOTTI, R. (Eds.). Football in Africa: conflict, conciliation and community. New York: : Palgrave MacMillan, 2004. p.229-46. BELELI, I. Corpo e identidade na propaganda. Estudos Feministas, Florianópolis, v.15, n.1, p.193-215, 2007.

BOECHAT, Y.; CARDOSO, R. Copa fashion: mesmo sem pagar um tostão à FIFA, Nike e Puma, chamam a atenção dos torcedores com uniformes apertados e chuteiras espalhafatosas - e fazem mais barulho até do que os patrocinadores oficiais do evento. ISTOÉ Dinheiro, São Paulo, 25 jun. 2010. Disponível em: <http://www.istoedinheiro.com.br/noticias/26738_COPA+FASHION>. Acesso em: 22 dez. 2010. CATHUS, O. O preconceito forte como um leão: representaçôes do negro e da violência na mídia. Revista FAMECOS, Porto Alegre, v.1, n.29, p.111-21, 2006.

CERRI, L.F. Vendendo o peixe. Revista de História da Biblioteca Nacional, Rio de Janeiro, ano 1, n.11, p.83-6, 2006. DARBY, P. Africa, football and FIFA: politics, colonialism and resistance. London: Frank Cass, 2002.

. Migração para Portugal de jogadores de futebol africanos: recurso colonial e neocolonial. Análise Social, Lisboa, v.41, n.179, p.417-33, 2006.

DARBY, P.; AKINDES, G.; KIRWIN, M. Football academies and the migration of African football labor to Europe. Journal of Sport \& Social Issue, Champaign, v.31, n.2, p.143-61, 2007.

DUERKSEN, S.; MIKAIL, A.; TOM, L.; PATTON, A.; LOPEZ, J.; AMADOR, X.; VARGAS, R.; VICTORIO, M.; KUSTIN, B.; SADLER, G.R. Health disparities and advertising content of women's magazines: a cross-sectional study. BMC Public Health, London, v.5, p.85-94, 2005.

FERRARESI, A.L.; FRANZONI, A.M.B.; HELOU FILHO, E.A.; ROTHBARTH, M.F.; OTANI, N.; WOLF, S.M.; FOTOS das camisas da Copa do Mundo de 2010, As. Época, Rio de Janeiro, 30 abr. 2010. Disponível em: <http:// revistaepoca.globo.com/Revista/Epoca/0,EMI137119-17820,00.html> Acesso em: 22 dez. 2010.

FRANCISCO, T.H.A. Gestão de marcas: um estudo de caso da PUMA. In: CONGRESO DE INVESTIGACIÓN Y CREACION INTElECTUAL, 7., 2010, Caracas. Anais... Caracas: Universidad Metropolitana, 2010.

GIARDINA, M.D. One day, one goal? PUMA, corporate philanthropy and the cultural politics of brand 'Africa'. Sport in Society, London, v.13, n.1, p.130-42, 2010.

GISELE Bündchen aparece super sensual em ensaio fotográfico. Revista Quem, Rio de Janeiro, 7 abr. 2009. Semanal. Disponível em: <http://revistaquem.globo.com/Revista/Quem/0,EMI67434-8197,00-GISELE+BUNDCHEN+APAR ECE+SUPER+SENSUAL+EM+ENSAIO+FOTOGRAFICO.html> Acesso em: 20 dez. 2010.

GIULIANOTTI, R. Os estudos do esporte no continente africano. In: MELO, V.A.; BITTENCOURT, M.; NASCIMENTO, A. (Orgs.). Mais do que um jogo: o esporte no continente africano. Rio de Janeiro: Apicuri, 2010. 
. Sport and social development in Africa: some major human rights issues. In: INTERNATIONAL CONFERENCE ON SPORTS AND HUMAN RIGHTS, 1., 1999, Sidney. Proceedings... Sydney: Human Rights Council of Australia, 1999. GUERRA, M.O. O jogo da moda: a transformação do futebol em negócio. In: ENCONTRO REGIONAL DE COMUNICAÇÃO, 1., 2003, Juiz de Fora. Anais... Juiz de Fora: UFJF, 2003.

HOBSBAWM, E. Globalização, democracia e terrorismo. São Paulo: Companhia das Letras, 2007.

HONORATO, M. Conheça o time de bonitōes da Copa. ODIA Online, Rio de Janeiro, 3 jul. 2010. Disponível em: <http://odia. terra.com.br/portal/ataque/copa2010/html/2010/7/conheca_o_time_de_bonitoes_da_copa_93252.html>Acesso em: 22 dez. 2010. MALDONADO, G.R. A educação física e o adolescente: a imagem corporal e a estética da transformação na mídia impressa. Revista Mackenzie de Educação Física e Esporte, São Paulo, v.5, n.1, p.59-76, 2006.

MELO, V.A. Esporte e lazer: conceitos. Rio de Janeiro: Apicuri/FAPERJ, 2010.

. Jogos de identidade: o esporte em Cabo Verde. Rio de Janeiro: Apicuri/CNPq, 2011.

PACHECO, H.P. Representatividade da imagem do negro nos meios de comunicação: revista Raça Brasil e a imprensa brasileira. In: CONGRESSO BRASILEIRO DE CIÊNCIAS DA COMUNICAÇÃO, 24., 2001, Campo Grande. Anais... Campo Grande: Sociedade Brasileira de Estudos Interdisciplinares da Comunicação, 2001.

PALMA, A.; ASSIS, M.; LACERDA, Y.; BAGRICHEVSKY, M.; SAMPAIO, K.S. Culto ao corpo e exposição de produtos na mídia especializada em estética e saúde. Movimento, Porto Alegre, v.16, n.1, p.31-51, 2010.

POLI, R. Migrations and trade of African football players: historic, geographical and cultural aspects. Afrika Spectrum, Hamburg, v.41, n.3, p.393-414, 2006.

PUMA BRASIL. Conheça as novas camisetas das seleçóes africanas. 15 fev. 2010a. Disponível em: <http://brasil.puma. com/albums/v1-10-conheca-as-novas-camisetas-das-selecoes-africanas> Acesso em: 22 dez. 2010.

Parabenizamos o Uruguai por ficar em quarto lugar na Copa do Mundo. 14 jul. 2010b. Disponível em: <http://brasil.puma.com/albums/parabenizamos-o-uruguai-por-ficar-em-quarto-lugar> Acesso em: 22 dez. 2010.

RAMOS, C.B. As identidades culturais na publicidade: o caso Coca-Cola na Copa do Mundo 2010. In: CONGRESSO BRASILEIRO DE CIÊNCIAS DA COMUNICAÇÃO, 33., 2010, Caxias do Sul. Anais... Caxias do Sul: Sociedade Brasileira de Estudos Interdisciplinares da Comunicação, 2010.

ROSO, A.; STREY, M.N.; GUARESCHI, P.; BUENO, S.M.N. Cultura e ideologia: a mídia revelando estereótipos raciais de gênero. Psicologia \& Sociedade, Florianópolis, v.14, n.2, p.74-94, 2002.

SABAT, R. Gênero e sexualidade para consumo. In: LOURO, G.L.; NECKEL, J.F.; GOELLNER, S.V. Corpo, gênero e sexualidade: um debate contemporâneo na educação. Petrópolis: Vozes, 2003. p. 149-159.

SANT'ANNA, D.B. Propaganda e história: antigos problemas, novas questōes. Projeto História, São Paulo, n.14, p.89-112, 1997. STROZNBERG, I. Branca, preta, híbrida: qual é a cor da beleza na propaganda brasileira hoje? ComCiência: Revista Eletrônica de Jornalismo Científico, Campinas, n. 78, jul. 2006. Disponível em: <http://www.comciencia.br/comciencia/ handler.php?section=8\&edicao=15\&id=148> Acesso em: 20 dezembro 2010 .

O apelo da cor: percepções dos consumidores sobre as imagens da diferença racial na propaganda brasileira.

Comunicação, Mídia e Consumo, São Paulo, v.2, n.4, p.199-220, 2005.

TOLEDO, L.H. Pelé: os mil corpos de um rei. In: GARGANTA, J.; OLIVEIRA, J.; MURAD, M. (Orgs.). Futebol de muitas cores e sabores: reflexões em torno do desporto mais popular do mundo. Porto: Campo das Letras, 2004. p.147-66. VASCONCELOS, L. Disputa pela mais bela camisa da Copa do Mundo: a rivalidade das grandes grifes do esporte. Colherada cultural, 26 jun. 2010. Disponível em: <http://www.colheradacultural.com.br/content/20100625214407.000.13-N.php>Acesso em: 22 dez. 2010. VELHO, B.A.; BACELLAR, F.C.T. Algo de novo no ar: a representação de homens e de mulheres na propaganda. In: CONGRESSO BRASILEIRO DE CIÊNCIAS DA COMUNICAÇÃO, 26., 2003, Belo Horizonte. Anais... Belo Horizonte: Sociedade Brasileira de Estudos Interdisciplinares da Comunicação, 2003.

YOUNG, R.J.C. Postcolonialism: an historical introduction. Oxford: Blackwell, 2001.

ENDEREÇO

Victor Andrade de Melo

Programa de Pós-Graduação em História Comparada/ IFCS Universidade Federal do Rio de J aneiro Largo de São Francisco, n.1, sala 31 - Centro 20051-070 - Rio deJ aneiro - RJ - BRASIL e-mail: victor.a.melo@uol.com.br

Recebido para publicação: 14/ 02/ 2011

1a. Revisão: 25/04/2011

2a. Revisão: 27/04/2011

Aceito: 28/04/2011 